\title{
Crystal Polymorphism of Protein GB1 Examined by Solid-State NMR Spectroscopy and X-ray Diffraction
}

Heather L. Frericks Schmidt, Lindsay J. Sperling, Yi Gui Gao, John M. Boettcher, Benjamin J. Wylie, Scott R. Wilson, and Chad M. Rienstra*

*Corresponding Author: rienstra@scs.uiuc.edu

\section{Supporting Information}

\section{a. Chemical shift assignments of GB1 microcrystalline formulation D and E}

Backbone chemical shifts were assigned for GB1 microcrystalline forms D and E using 3D NCOCX, 3D NCACX, 2D N(CO)CX and 2D N(CA)CX and de novo backbone walk methods on uniformly- ${ }^{13} \mathrm{C},{ }^{15} \mathrm{~N}$-labeled GB1 samples. The chemical shifts for the previously assigned microcrystalline form A of GB1 (BMRB ID: 15156) were used to assist in the assignments, ${ }^{1}$ but in all cases complete correlation information was obtained experimentally and analyzed by standard methods. Longer mixing times (greater than $25 \mathrm{~ms}$ of DARR mixing ${ }^{2}$ ) were used in these experiments to observe signals for the complete sidechain. In addition, numerous interresidue correlations were observed for these samples, owing to the high sensitivity. To avoid errors in backbone assignments for this reason, all peaks with sensitivity of at least 9 times the RMS noise were first assigned, then contour levels in Sparky were set to 5 times the noise floor to identify weak peaks and interresidue correlations. Complete sidechain aliphatic ${ }^{13} \mathrm{C}$ chemical shifts were assigned using the 3D NCOCX and NCACX with long DARR mixing ${ }^{2}$ periods and ${ }^{13} \mathrm{C}-{ }^{13} \mathrm{C}$ correlation experiments, using $25 \mathrm{~ms}$ of DARR mixing ${ }^{2}$ and two supercycles of SPC-5 mixing ${ }^{3,4}$ (1 ms total), to discern between multi-bond and one-bond correlations. The assigned backbone and chemical shifts for microcrystalline forms D and E are provided in Table S1 and Table S2, respectively. All assigned chemical shifts were confirmed in a minimum of three spectra. 


\section{b. Chemical shifts assignments of lysine sidechains}

Chemical shift assignments of the lysine sidechains were completed using $\mathrm{N}(\mathrm{CE}) \mathrm{CX}$ spectra of form D and E (Figure S1), using conditions similar to N(CA)CX spectra but focusing on the region of the ${ }^{15} \mathrm{~N}$ spectrum near $35 \mathrm{ppm}$. The lysine NZ shift was first identified by crosspeaks with previously assigned lysine $\mathrm{CB}, \mathrm{CG}$ or $\mathrm{CD}$ resonances. Next the lysine NZ resonance was used to identify the $\mathrm{CE}$ resonance. Complete lysine chemical shift assignments for form $\mathrm{D}$ and $\mathrm{E}$ are given in Table $\mathrm{S} 1$ and $\mathrm{S} 2$, respectively. The $\mathrm{N}(\mathrm{CE}) \mathrm{CX}$ experiment was completed with cross polarization at the following conditions: ${ }^{1} \mathrm{H}^{-15} \mathrm{~N}$ cross polarization $(\mathrm{CP})$ to polarize all ${ }^{15} \mathrm{~N}$ resonances followed by ${ }^{15} \mathrm{~N}-{ }^{13} \mathrm{C}$ SPECIFIC $\mathrm{CP}^{5}$ from the lysine $\mathrm{NZ}$ to CE, implemented with tangent ramped cross polarization $6 .{ }^{15} \mathrm{~N}-{ }^{13} \mathrm{C}$ SPECIFIC CP ${ }^{5}$ was achieved using the $1 / 4 \omega_{\mathrm{R}}$ on ${ }^{15} \mathrm{~N}$ and $3 / 4 \omega_{\mathrm{R}}$ on ${ }^{13} \mathrm{C}$, resulting in a double quantum Hartmann-Hahn condition with the ${ }^{15} \mathrm{~N}$ carrier at $34 \mathrm{ppm}$ and the ${ }^{13} \mathrm{C}$ carrier at $45 \mathrm{ppm}$.
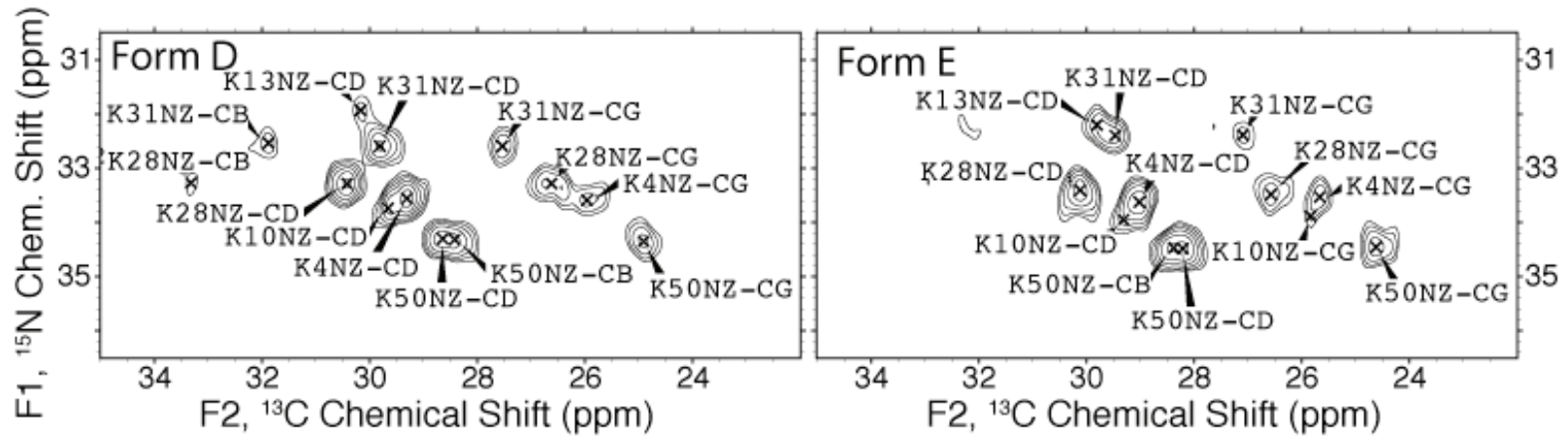

Figure S1. Lysine N(CE)CX spectra of forms D and E

Completed using SPECIFIC CP $\mathrm{CP}^{5}$ from lysine NZ to CE followed by $90 \mathrm{~ms}$ of $\mathrm{DARR}^{2}$ mixing to transfer polarization to lysine sidechain atoms. The form $\mathrm{D}$ spectrum was acquired for $6 \mathrm{~h}$ with $38.4 \mathrm{~ms}$ of acquisition and $14.4 \mathrm{~ms}$ of total $\mathrm{t}_{1}$ evolution (160 rows TPPI; dwell time $=180 \mu \mathrm{s}$ ). The form E spectrum was acquired for $8.3 \mathrm{~h}$ with $38.4 \mathrm{~ms}$ of acquisition and $11.5 \mathrm{~ms}$ of total $\mathrm{t}_{1}$ evolution (128 rows TPPI; dwell time=180 $\mu$ s). Data are shown with $15 \mathrm{~Hz}(\mathrm{~F} 2)$ and $20 \mathrm{~Hz}(\mathrm{~F} 1)$ Lorenzian-to-Gaussian apodization applied, zero filling to 8192 (F2) X 4096 (F1) points and forward linear prediction in $\mathrm{F} 1\left({ }^{15} \mathrm{~N}\right)$ dimension. 
Table S1. GB1 Microcrystalline Form D Chemical Shifts

\begin{tabular}{|c|c|c|c|c|c|c|c|c|c|c|}
\hline & $\mathrm{N}$ & $\mathrm{C}^{\prime}$ & $\mathrm{CA}$ & $\mathrm{CB}$ & $\mathrm{CG}$ & $\mathrm{CD}$ & $\mathrm{CE}$ & $\mathrm{ND}$ & $\mathrm{NE}$ & $\mathrm{NZ}$ \\
\hline M1 & 40.04 & 171.38 & 54.27 & 32.45 & 30.17 & & 15.86 & & & \\
\hline Q2 & 125.29 & 174.95 & 55.80 & 30.42 & 35.29 & 180.29 & & & 113.27 & \\
\hline Y3 & 123.23 & 174.90 & 56.89 & 43.46 & & & & & & \\
\hline $\mathrm{K} 4$ & 122.78 & 173.23 & 54.81 & 36.24 & 25.52 & 28.96 & 42.14 & & & 33.19 \\
\hline L5 & 127.03 & 174.78 & 52.91 & 42.46 & 27.33 & $\begin{array}{l}25.71 \\
25.05\end{array}$ & & & & \\
\hline L7 & 127.06 & 175.13 & 54.62 & 42.92 & 27.07 & $\begin{array}{l}26.14 \\
25.08\end{array}$ & & & & \\
\hline N8 & 125.14 & 176.37 & 50.70 & 38.29 & 176.51 & & & 110.70 & & \\
\hline G9 & 109.59 & 173.14 & 44.60 & & & & & & & \\
\hline $\mathrm{K} 10$ & 121.04 & 179.12 & 59.23 & 32.86 & 25.71 & 29.22 & 42.21 & & & 33.5 \\
\hline K13 & 123.30 & 175.72 & 53.35 & 38.92 & 26.08 & 29.76 & 43.02 & & & 31.52 \\
\hline G14 & 105.56 & 171.35 & 44.93 & & & & & & & \\
\hline E15 & 120.98 & 174.15 & 53.87 & 34.25 & 35.46 & 181.96 & & & & \\
\hline T16 & 115.07 & 171.98 & 60.05 & 70.40 & 20.04 & & & & & \\
\hline T17 & 116.03 & 174.30 & 60.27 & 72.61 & 21.79 & & & & & \\
\hline T18 & 116.10 & 171.20 & 61.30 & 70.85 & 18.86 & & & & & \\
\hline E19 & 125.50 & 175.83 & 54.28 & 30.80 & 35.92 & 182.32 & & & & \\
\hline A20 & 125.68 & 177.71 & 50.67 & 23.64 & & & & & & \\
\hline V21 & 116.40 & 174.92 & 63.51 & 31.91 & $\begin{array}{l}21.01 \\
20.70\end{array}$ & & & & & \\
\hline D22 & 115.45 & 175.03 & 52.48 & 42.34 & 179.77 & & & & & \\
\hline A23 & 122.43 & 179.56 & 54.42 & 18.24 & & & & & & \\
\hline A24 & 120.77 & 181.40 & 54.51 & 18.23 & & & & & & \\
\hline $\mathrm{T} 25$ & 117.40 & 175.86 & 67.43 & 67.80 & 21.40 & & & & & \\
\hline A26 & 123.77 & 177.23 & 54.97 & 17.48 & & & & & & \\
\hline E27 & 116.31 & 177.75 & 59.10 & 28.99 & 35.48 & 181.49 & & & & \\
\hline $\mathrm{K} 28$ & 117.38 & 179.09 & 60.19 & 32.77 & 26.37 & 30.08 & 42.31 & & & 32.92 \\
\hline V29 & 119.23 & 178.88 & 66.26 & 31.89 & $\begin{array}{l}22.21 \\
20.99\end{array}$ & & & & & \\
\hline F30 & 118.80 & 179.23 & 57.42 & 37.39 & & & & & & \\
\hline K31 & 120.59 & 179.59 & 60.11 & 30.60 & 27.31 & 29.40 & 41.18 & & & 32.21 \\
\hline Q32 & 121.29 & 177.52 & 58.82 & 28.89 & 34.12 & 179.86 & & & 115.71 & \\
\hline Y33 & 120.94 & 178.68 & 61.54 & 36.87 & & & & & & \\
\hline A34 & 122.67 & 179.55 & 56.05 & 18.04 & & & & & & \\
\hline N35 & 118.14 & 179.53 & 57.06 & 39.32 & 175.96 & & & 113.28 & & \\
\hline D36 & 121.15 & 176.17 & 55.90 & 38.26 & 177.66 & & & & & \\
\hline N37 & 115.05 & 174.24 & 53.52 & 40.29 & 176.79 & & & 114.48 & & \\
\hline G38 & 108.44 & 174.00 & 46.85 & & & & & & & \\
\hline V39 & 121.77 & 175.14 & 61.74 & 31.88 & $\begin{array}{l}21.94 \\
21.94\end{array}$ & & & & & \\
\hline D40 & 131.11 & 174.92 & 52.74 & 41.70 & 180.79 & & & & & \\
\hline G41 & 108.23 & 172.70 & 45.18 & & & & & & & \\
\hline E42 & 119.21 & 177.82 & 55.20 & 31.57 & 35.98 & 182.13 & & & & \\
\hline W43 & 125.00 & 177.37 & 57.49 & 33.90 & & & & & & \\
\hline T44 & 109.11 & 173.94 & 60.84 & 73.04 & 21.00 & & & & & \\
\hline Y45 & 118.69 & 171.89 & 57.81 & 43.00 & & & & & & \\
\hline D46 & 126.38 & 176.34 & 50.86 & 42.68 & 180.23 & & & & & \\
\hline D47 & 123.55 & 177.36 & 54.72 & 43.02 & 179.60 & & & & & \\
\hline A48 & 119.01 & 179.64 & 54.04 & 18.99 & & & & & & \\
\hline T49 & 104.01 & 175.68 & 60.23 & 69.91 & 21.57 & & & & & \\
\hline K50 & 119.96 & 175.45 & 55.58 & 27.99 & 24.40 & 28.22 & 43.38 & & & 33.95 \\
\hline T51 & 112.00 & 174.36 & 62.45 & 71.65 & 21.24 & & & & & \\
\hline F52 & 130.31 & 175.71 & 56.51 & 42.78 & & & & & & \\
\hline T53 & 112.15 & 172.19 & 60.31 & 71.66 & 21.03 & & & & & \\
\hline V54 & 118.34 & 172.59 & 58.40 & 32.67 & $\begin{array}{l}21.83 \\
19.68\end{array}$ & & & & & \\
\hline T55 & 124.11 & 174.18 & 61.25 & 72.04 & 21.35 & & & & & \\
\hline E56 & 131.06 & 180.55 & 57.57 & 33.24 & 38.80 & 183.17 & & & & \\
\hline
\end{tabular}

Frericks Schmidt et al. 
Table S2. GB1 Microcrystalline Form E Chemical Shifts

\begin{tabular}{|c|c|c|c|c|c|c|c|c|c|c|}
\hline & $\mathrm{N}$ & $C^{\prime}$ & $\mathrm{CA}$ & $\mathrm{CB}$ & $\mathrm{CG}$ & $\mathrm{CD}$ & $\mathrm{CE}$ & ND & $\mathrm{NE}$ & $\mathrm{NZ}$ \\
\hline M1 & 39.98 & 171.29 & 54.28 & 32.32 & 30.10 & & 15.87 & & & \\
\hline Q2 & 125.00 & 174.89 & 55.66 & 30.59 & 35.35 & 180.27 & & & 113.26 & \\
\hline Y3 & 123.02 & 174.87 & 56.99 & 43.68 & & & & & & \\
\hline K4 & 122.55 & 173.23 & 54.82 & 36.21 & 25.51 & 28.98 & 42.19 & & & 33.54 \\
\hline L5 & 126.71 & 174.84 & 52.96 & 42.57 & 27.35 & $\begin{array}{l}25.85 \\
25.03\end{array}$ & & & & \\
\hline I6 & 126.05 & 175.29 & 59.89 & 37.87 & $\begin{array}{l}27.39 \\
17.59\end{array}$ & 12.70 & & & & \\
\hline L7 & 126.78 & 175.03 & 54.64 & 43.03 & 27.18 & $\begin{array}{l}26.09 \\
25.16\end{array}$ & & & & \\
\hline N8 & 124.80 & 176.40 & 50.64 & 38.28 & 176.48 & & & 110.41 & & \\
\hline G9 & 109.30 & 173.32 & 44.59 & & & & & & & \\
\hline $\mathrm{K} 10$ & 120.62 & 179.08 & 59.08 & 32.79 & 25.70 & 29.22 & 42.43 & & & 33.90 \\
\hline $\mathrm{T} 11$ & 106.48 & 173.21 & 61.93 & 69.56 & 22.65 & & & & & \\
\hline L12 & 127.19 & 173.95 & 54.39 & 43.28 & 27.96 & $\begin{array}{l}26.06 \\
23.09\end{array}$ & & & & \\
\hline K13 & 122.93 & 175.78 & 53.33 & 38.89 & 26.01 & 29.81 & 42.94 & & & 31.98 \\
\hline G14 & 105.42 & 171.22 & 44.98 & & & & & & & \\
\hline E15 & 120.65 & 174.17 & 53.81 & 33.99 & 34.81 & 181.94 & & & & \\
\hline T16 & 115.05 & 172.00 & 60.04 & 70.45 & 20.08 & & & & & \\
\hline $\mathrm{T} 17$ & 115.37 & 174.40 & 60.15 & 72.64 & 21.82 & & & & & \\
\hline $\mathrm{T} 18$ & 115.61 & 171.39 & 61.43 & 70.81 & 18.87 & & & & & \\
\hline E19 & 125.07 & 175.89 & 54.50 & 30.88 & 36.04 & 182.44 & & & & \\
\hline A20 & 124.73 & 177.74 & 50.74 & 23.51 & & & & & & \\
\hline V21 & 115.80 & 175.00 & 63.61 & 32.00 & $\begin{array}{l}21.41 \\
20.24\end{array}$ & & & & & \\
\hline D22 & 115.05 & 175.03 & 52.65 & 42.37 & 179.79 & & & & & \\
\hline A23 & 122.40 & 179.55 & 54.49 & 18.29 & & & & & & \\
\hline A24 & 120.64 & 181.40 & 54.55 & 18.33 & & & & & & \\
\hline $\mathrm{T} 25$ & 116.95 & 175.84 & 67.41 & 67.79 & 21.51 & & & & & \\
\hline A26 & 123.63 & 177.34 & 54.99 & 17.45 & & & & & & \\
\hline E27 & 116.11 & 177.82 & 59.17 & 29.05 & 35.53 & 181.52 & & & & \\
\hline $\mathrm{K} 28$ & 117.06 & 179.11 & 60.23 & 32.76 & 26.47 & 29.99 & 42.36 & & & 33.37 \\
\hline V29 & 118.96 & 178.81 & 66.30 & 31.90 & $\begin{array}{l}22.29 \\
21.03\end{array}$ & & & & & \\
\hline F30 & 118.44 & 179.10 & 57.47 & 37.38 & & & & & & \\
\hline K31 & 120.51 & 179.64 & 60.13 & 31.69 & 27.17 & 29.39 & 41.24 & & & 32.33 \\
\hline Q32 & 121.00 & 177.55 & 58.87 & 28.93 & 34.15 & 179.83 & & & 115.58 & \\
\hline Y33 & 120.70 & 178.66 & 61.52 & 37.62 & & & & & & \\
\hline A34 & 122.45 & 179.64 & 56.08 & 18.14 & & & & & & \\
\hline N35 & 118.07 & 179.57 & 57.04 & 39.30 & 176.05 & & & 113.38 & & \\
\hline D36 & 121.10 & 176.24 & 55.94 & 38.30 & 177.71 & & & & & \\
\hline N37 & 114.83 & 174.33 & 53.53 & 40.33 & 176.80 & & & 114.27 & & \\
\hline G38 & 108.37 & 174.08 & 46.90 & & & & & & & \\
\hline V39 & 121.47 & 175.15 & 61.71 & 31.87 & $\begin{array}{l}21.98 \\
21.98\end{array}$ & & & & & \\
\hline D40 & 130.70 & 175.07 & 52.77 & 41.78 & 180.89 & & & & & \\
\hline G41 & 108.30 & 172.70 & 45.14 & & & & & & & \\
\hline E42 & 119.03 & 177.85 & 55.25 & 31.53 & 36.12 & 181.95 & & & & \\
\hline W43 & 125.04 & 177.32 & 57.52 & 33.74 & & & & & & \\
\hline T44 & 108.98 & 173.93 & 60.89 & 73.03 & 21.01 & & & & & \\
\hline Y45 & 118.42 & 171.89 & 57.87 & 42.96 & & & & & & \\
\hline D46 & 126.05 & 176.26 & 50.84 & 42.63 & 180.12 & & & & & \\
\hline D47 & 123.42 & 177.41 & 54.83 & 43.11 & 176.63 & & & & & \\
\hline A48 & 118.77 & 179.63 & 54.13 & 18.99 & & & & & & \\
\hline T49 & 103.68 & 175.70 & 60.22 & 69.97 & 21.67 & & & & & \\
\hline K50 & 119.88 & 175.47 & 55.63 & 28.10 & 24.43 & 28.22 & 43.38 & & & 34.36 \\
\hline T51 & 111.87 & 174.42 & 62.45 & 71.67 & 21.32 & & & & & \\
\hline F52 & 129.94 & 175.79 & 56.59 & 43.30 & & & & & & \\
\hline T53 & 111.87 & 172.26 & 60.25 & 71.88 & 21.17 & & & & & \\
\hline V54 & 118.00 & 172.60 & 58.46 & 32.69 & $\begin{array}{l}21.84 \\
19.69\end{array}$ & & & & & \\
\hline T55 & 123.84 & 174.23 & 61.27 & 72.02 & 21.45 & & & & & \\
\hline E56 & 130.79 & 180.63 & 57.62 & 33.17 & 38.72 & 183.22 & & & & \\
\hline
\end{tabular}

Frericks Schmidt et al. 


\section{c. Comparison of Assigned Form A, D and E Chemical Shifts}

All of the CA (Figure S2a) and C' (Figure S2b) chemical shift values were highly conserved among form A, form D and form E. The consistent CA isotropic chemical shifts demonstrate a constant backbone conformation among all forms. Significant changes of backbone structure would certainly be observed in the CA isotropic chemical shifts, given the high experimental precision inherent to the $\sim 0.2 \mathrm{ppm}$ inhomogeneous linewidth. ${ }^{7-14}$ Likewise, C' chemical shifts, while not as sensitive to dihedral angles, are exceptionally sensitive to the hydrogen bond length, ${ }^{15-17}$ and any structural changes which would alter the hydrogen bonding networks would result in a corresponding C' chemical shift perturbation.
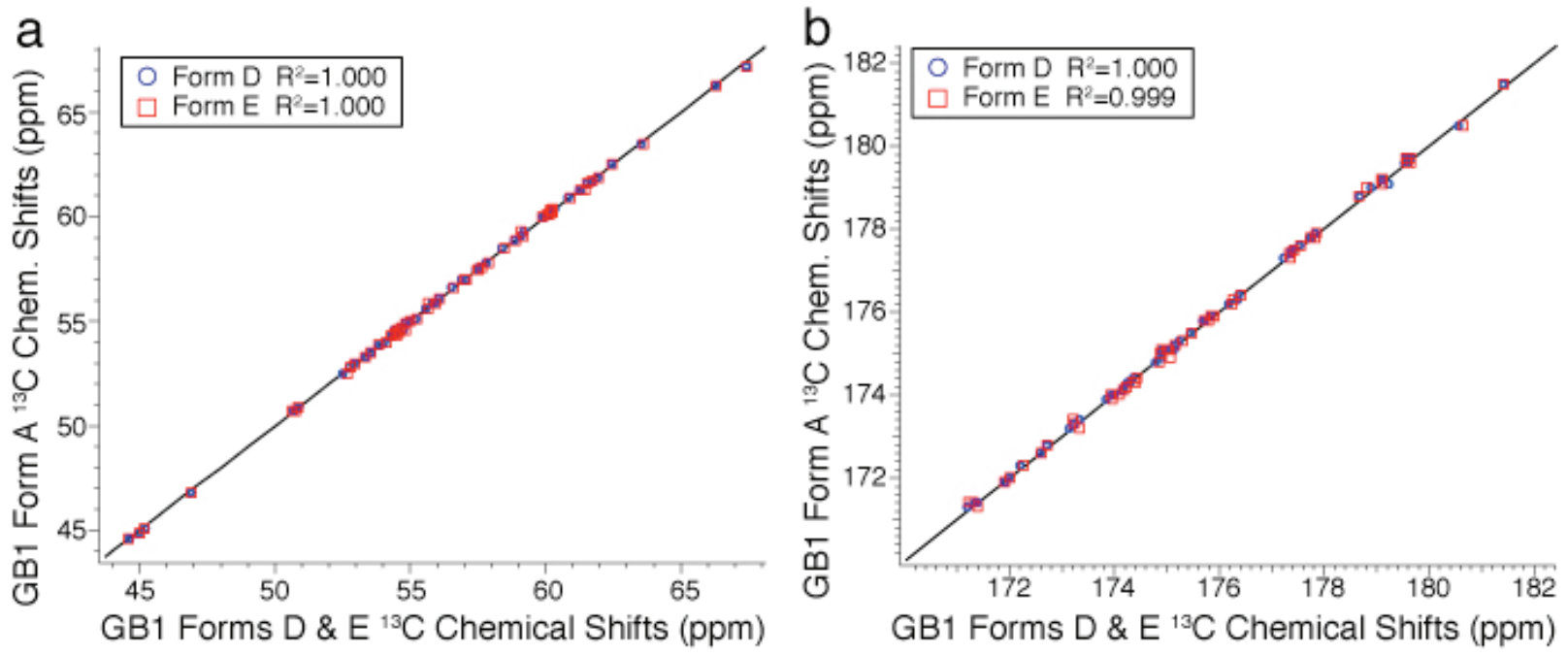

Figure S2. CA and C' chemical shifts of GB1 form A versus forms D and E (a) CA and (b) C' chemical shifts plotted for formulation A verses form D (shown in blue circles) and form A verses form $\mathrm{E}$ (red squares). 

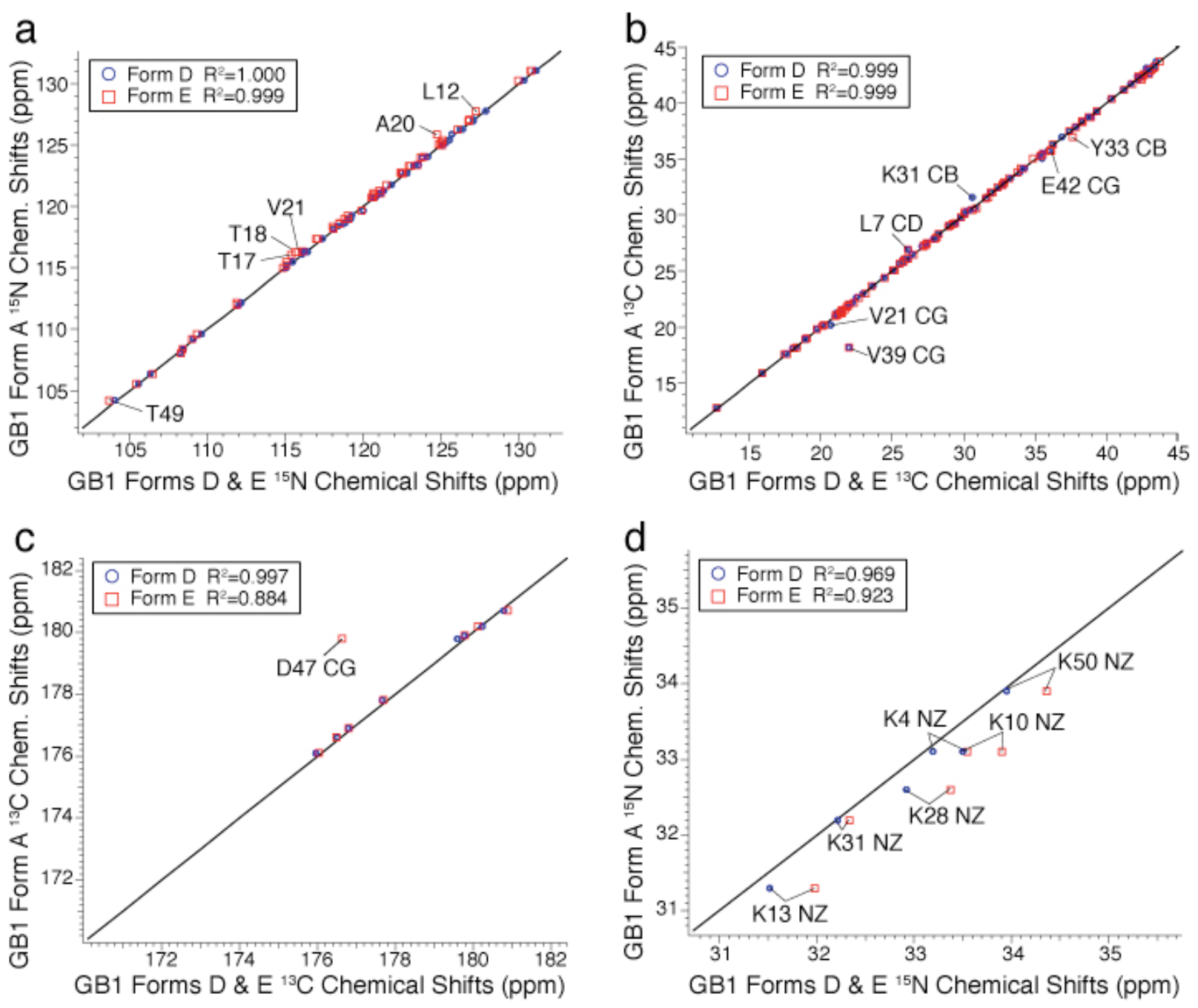

Figure S3. Backbone amide and Sidechain chemical shifts of GB1 form A verses forms D and $\mathbf{E}$ (a) Backbone amide resonances with residues that differ by more than $0.5 \mathrm{ppm}$ from form A are indicated. (b) Aliphatic and (c) carbonyl sidechain resonances with form $\mathrm{D}$ and form $\mathrm{E}$ resonances differing by \pm 0.4 ppm from form A labeled. (d) Lysine NZ shifts.

Larger variations were observed for the backbone ${ }^{15} \mathrm{~N}$ chemical shifts (Figure S3a), which are highly dependent on the hydrogen bonding of the amide proton, solvent buffer $\mathrm{pH}$ and ion concentration, dihedral angles of the backbone of the residue as well as its preceding residue, in addition to crystal packing effects that may alter long-range electrostatics (on the order of 5 $\AA$ ). ${ }^{18-21}$ Because the $\mathrm{CA}$ and C' shifts reveal no statistically significant changes among the various microcrystalline preparations of GB1, the backbone ${ }^{15} \mathrm{~N}$ chemical shift perturbations must in this case be a function of ionic strength of the buffer solution, local $\mathrm{pH}$, and crystal 
packing. Previous studies by Paulson et al. ${ }^{20}$ showed similar perturbations of amide shifts resulting from a polymorphic sample preparation of ubiquitin. The subsequent study by Seidel et al. ${ }^{22}$ revealed some backbone ${ }^{13} \mathrm{C}$ chemical shift differences between these two polymorphs, the differences were not correlated to residues showing ${ }^{15} \mathrm{~N}$ perturbation, indicating that amide resonances exposed to solvent in microcrystalline preparations are exceptionally sensitive to sample preparation conditions. In the present study, those backbone amide resonances showing substantial deviations (L12, T17, T18, A20, V21, T49) are all in solvent exposed regions of the protein, near crystal contacts, where intermolecular contacts, buffer ions, and local $\mathrm{pH}$ differences would be accentuated.

The charged and aliphatic sidechain resonances of forms D and E (Figure S3 b-d) also display variations in chemical shift from the form A resonances. The most substantial of these isotropic chemical shift differences are for the methyl groups of V21, V39 and L7. It is well know that the CA shifts of beta-branched amino acid residues show a strong dependence upon chi $_{1}$ in addition to phi and psi. ${ }^{23-26}$ As no change in CA is observed, these chemical shift differences must result from crystal packing and ionic strength. The sidechains of all these residues are external to the protein, increasing their exposure to solvent and changes in the crystal contacts in which they likely participate. This argument is strengthened by the observation that V54, which is packed within the hydrophobic core of the protein, shows little changes among the various preparations. Other examples of sidechain chemical shift differences are for residues with charged sidechains such as K10, K13, K28 and D47 where the buffer composition is the likely cause of different experimental shifts. Although differences exist among the forms, the overall correlation is very good $\left(\mathrm{R}^{2}\right.$ values for these plots are all above 0.88 ), indicating that the protein structure is conserved and the observed differences are due to local perturbations. 


\section{c. Identification of buffer and co-solvent molecules in the GB1 trigonal single crystal}

\section{structure}

The high-resolution electron density map of the GB1 trigonal crystal structure displays the atom positions of the 2-propanol (Figure S4a), phosphate ion (Figure S4b) and 2-

methylpentane-2,4-diol (Figure S4c) molecules. The trigonal crystal structure (PDB ID: 2QMT) was refined using molecular replacement based upon the Gallagher et al. ${ }^{27}$ orthorhombic (PDB ID: 1PGA) structure with the addition of two 2-propanol molecules, one 2-methylpentane-2,4diol molecule and one phosphate ion, using the Amore program within the CCP4 package ${ }^{28}$ under the conditions given in Table S3.
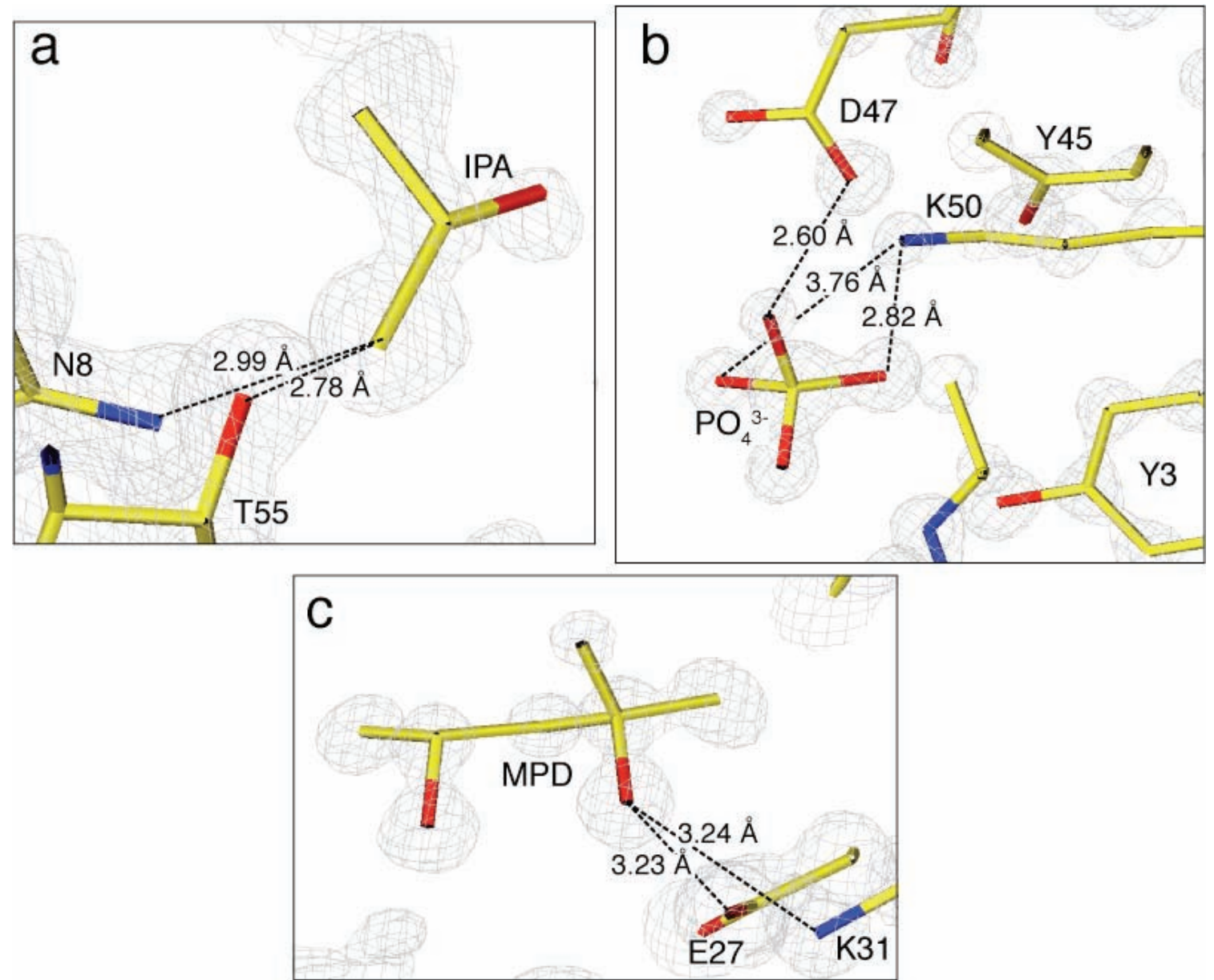

Figure S4. Expansions of electron density map for GB1 trigonal single crystal structure. Electron density for (a) one of the two 2-propanol (IPA) molecules, (b) one phosphate ion $\left(\mathrm{PO}_{4}{ }^{3-}\right)$ and (c) one 2-methylpentane-2,4-diol (MPD) molecule are shown. Figure created using $\mathrm{O}$ (Jones, T.A. and Kjeldgaard, M.K.). 
Table S3. Refinement Statistics for Crystal Forms of $\beta 1$ IgG-Binding Domain of Protein G

\begin{tabular}{|c|c|c|}
\hline Crystal & GB1 $^{\mathrm{a}}$ & $\mathrm{GB1}^{\mathrm{b}}$ \\
\hline \multicolumn{3}{|l|}{ Refinement Statistics } \\
\hline R-observe $(\%)(4 \sigma \mathrm{Fo})$ & 16.67 & 18.50 \\
\hline R-work $(\%)(4 \sigma F o)$ & 16.61 & 18.15 \\
\hline R-free $(\%)(4 \sigma F o)$ & 18.07 & 20.68 \\
\hline RMS Bond length $(\AA)$ & 0.013 & 0.016 \\
\hline RMS Bond angles $\left({ }^{\circ}\right)$ & 2.323 & 2.396 \\
\hline Total atoms of protein & 437 & 437 \\
\hline 2-Propanol (IPA) & 0 & 2 \\
\hline Phosphate ion $\left(\mathrm{PO}_{4}\right)^{-3}$ & 0 & 1 \\
\hline 2-methyl 2, 4-petanediol (MPD) & 0 & 1 \\
\hline Solvent (water) & 119 & 136 \\
\hline B average $\left(\AA^{2}\right)$ (protein atom only) & 15.182 & 14.491 \\
\hline \multicolumn{3}{|l|}{ Ramachandran plot (\%) } \\
\hline Most favored & 94.0 & 96.0 \\
\hline Additionally allowed regions & 6.0 & 4.0 \\
\hline
\end{tabular}

a: The reservoir contains $25 \mathrm{mM}$ Acetate $(\mathrm{pH}=3.8), 150 \mathrm{mM} \mathrm{NaCl}, 50 \% \mathrm{MPD}$ and 20\% IPA for Orthorhombic form (PDB ID:2GI9).

b: The reservoir contains $25 \mathrm{mM}$ Acetate $(\mathrm{pH}=4.5), 50 \mathrm{mM} \mathrm{NaCl}, 50 \% \mathrm{MPD}$ and $6 \%$ IPA for Trigonal form.

\section{d. Experimental Details of GB1 Powder X-ray Diffraction}

Powder data were collected on a Bruker (Bruker AXS, Inc., Madison, WI, USA) General Area Detector Diffraction System (GADDS). The Bruker P4Ra GADDS system generates radiation $(\mathrm{Cu} \mathrm{K \alpha}$ at $1.5418 \AA$ ) using a copper synchronous rotating anode and $0.3 / 3 \mathrm{~mm}$ cathode gun operating at a potential of $40 \mathrm{kV}$ with $50 \mathrm{~mA}$ filament current. The $\mathrm{P} 4 \mathrm{Ra}$ is equipped with a graphite monochromator, a 4-circle diffractometer, and a 10x10 cm Bruker HiStar multiwire area detector fitted with a helium beam tunnel. Each microcrystalline powder sample was mounted with excess mother liquor into a $1.5 \mathrm{~mm}$, thin-walled $(0.01 \mathrm{~mm})$, special glass capillary (Glaskapillaren, GLAS, Schönwalde, Germany). The microcrystalline powder was concentrated in the bottom of the capillary using a centrifuge before the tube was sealed with a low melting point wax. Data were collected at room temperature using a sample-to-detector distance of 252 
$\mathrm{mm}$ over three area frames (range $0^{\circ}<2 \theta<36^{\circ}$ ) for a total collection time of 180 minutes. The cylindrical capillary was optically aligned parallel to the phi-axis of the diffractometer then randomized by a rotation of $360^{\circ}$ about the spindle axis (phi). For each detector position in $2 \theta$, transmitted $\mathrm{CuK} \alpha$ photons were counted for the duration of phi randomization. Background photons scattered by air, glass, mother liquor, and to a lesser extent, Mylar ${ }^{\mathrm{TM}}$ and helium were removed from each combined frame by subtracting a mother liquor-filled capillary frame measured under the same conditions. The background corrected digital area frames were subsequently integrated over the optimal solid angle using a bin normalized $0.02^{\circ} 2 \theta$ step size (GADDS). The resultant $2 \theta$ versus integrated intensity $(\mathrm{x}-\mathrm{y})$ data from multiple frames were merged then truncated in $2 \theta$ (x) to eliminate the beam stop shadow. To compensate for scalar variation, the intensity component (y) of the data was normalized (Microsoft@ Excel, Microsoft Corp., Seattle, WA, USA) to fix the maximum value between 500 and $1000.2 \theta$ versus corrected integrated intensity (x-y) data were fit by Pawley refinement ${ }^{29}$ to GB1 orthorhombic and trigonal

unit cells using Diffrac ${ }^{\text {plus }}$ TOPAS (Bruker AXS GMBH, Karlsruhe, Germany). This curve fitting refinement included a Lorentz-polarization factor, a zero error correction, and a $1^{\text {st }}$-order Chebyshev polynomial baseline curve.

\section{References}

(1) Franks, W. T.; Zhou, D. H.; Wylie, B. J.; Money, B. G.; Graesser, D. T.; Frericks, H. L.; Sahota, G.; Rienstra, C. M. J. Am. Chem. Soc. 2005, 127, 12291-12305.

(2) Takegoshi, K.; Nakamura, S.; Terao, T. Chem. Phys. Lett. 2001, 344, 631-637.

(3) Hohwy, M.; Rienstra, C. M.; Jaroniec, C. P.; Griffin, R. G. J. Chem. Phys. 1999, 110, 7983-7992.

(4) Hohwy, M.; Rienstra, C. M.; Griffin, R. G. J. Chem. Phys. 2002, 117, 4973-4987.

(5) Baldus, M.; Petkova, A. T.; Herzfeld, J. H.; Griffin, R. G. Mol. Phys. 1998, 95, $1197-$ 1207.

(6) Hediger, S.; Meier, B. H.; Ernst, R. R. Chem. Phys. Lett. 1993, 213, 627-635.

(7) Spera, S.; Bax, A. J. Am. Chem. Soc. 1991, 113, 5490-5492.

(8) Cornilescu, G.; Delaglio, F.; Bax, A. J. Biomol. NMR 1999, 13, 289-302.

(9) Tjandra, N.; Bax, A. J. Amer. Chem. Soc. 1997, 119, 9576-9577. 
(10) Heller, J.; Laws, D. D.; Tomaselli, M.; King, D. S.; Wemmer, D. E.; Pines, A.; Havlin, R. H.; Oldfield, E. J. Am. Chem. Soc. 1997, 119, 7827-7831.

(11) Oldfield, E. J. Biomol. NMR 1995, 5, 217-225.

(12) Oldfield, E. Ann. Rev. Phys. Chem. 2002, 53, 349-378.

(13) Sun, H. H.; Sanders, L. K.; Oldfield, E. J. Am. Chem. Soc. 2002, 124, 5486-5495.

(14) Wylie, B. J.; Franks, W. T.; Graesser, D. T.; Rienstra, C. M. J. Am. Chem. Soc. 2005, 127, 11946-11947.

(15) Gu, Z. T.; Zambrano, R.; McDermott, A. J. Am. Chem. Soc. 1994, 116, 6368-6372.

(16) Takeda, N.; Kuroki, S.; Kurosu, H.; Ando, I. Biopolymers 1999, 50, 61-69.

(17) Lipsitz, R. S.; Tjandra, N. J. Am. Chem. Soc. 2001, 123, 11065-11066.

(18) Pujato, M.; Bracken, C.; Mancusso, R.; Cataldi, M.; Tasayco, M. L. Biophys. J. 2005, 89, 3293-3302.

(19) Khare, D.; Alexander, P.; Antosiewicz, J.; Bryan, P.; Gilson, M.; Orban, J. Biochemistry 1997, 36, 3580-3589.

(20) Paulson, E. K.; Morcombe, C. R.; Gaponenko, V.; Dancheck, B.; Byrd, R. A.; Zilm, K. W. J. Am. Chem. Soc. 2003, 125, 15831-15836.

(21) Kuroki, S.; Asakawa, N.; Ando, S.; Ando, I.; Shoji, A.; Ozaki, T. J. Mol. Struct. 1991, $245,69-80$.

(22) Seidel, K.; Etzkorn, M.; Heise, H.; Becker, S.; Baldus, M. Chembiochem 2005, 6, 16381647.

(23) Pearson, J. G.; Le, H. B.; Sanders, L. K.; Godbout, N.; Havlin, R. H.; Oldfield, E. J. Am. Chem. Soc. 1997, 119, 11941-11950.

(24) Straus, S. K.; Bremi, T.; Ernst, R. R. J. Biomol. NMR 1997, 10, 119-128.

(25) Havlin, R. H.; Le, H. B.; Laws, D. D.; deDios, A. C.; Oldfield, E. J. Am. Chem. Soc.

1997, 119, 11951-11958.

(26) Villegas, M. E.; Vila, J. A.; Scheraga, H. A. J. Biomol. NMR 2007, 37, 137-146.

(27) Gallagher, T.; Alexander, P.; Bryan, P.; Gilliland, G. L. Biochemistry 1994, 33, 47214729.

(28) Collaborative Computational Project, Number 4. Acta. Cryst. 1994, D50, 760-763.

(29) Pawley, G. S. J. Appl. Crystallogr. 1981, 14, 357-361. 